\title{
El estigma liberal en las elecciones presidenciales de Estados Unidos en 1988
}

\section{Sofía Gallardo}

La pérdida vertiginosa de popularidad de Michael Dukakis, en el proceso electoral norteamericano a la presidencia en 1988, produjo gran perplejidad entre los analistas políticos. En julio, todos los pronósticos le daban una ventaja de 17 puntos sobre George Bush. Pero en tan sólo tres meses las estimaciones se invirtieron y su fracaso fue contundente. ¿Qué fue lo que sucedió?

Aquí analizamos la derrota de Dukakis como un resultado de la campaña republicana de desprestigio del liberalismo. De aquí que no intentemos realizar un estudio exhaustivo y ponderado de los hechos, sino referirnos al significado negativo de lo liberal en el discurso de los republicanos. Nuestro objetivo es trascender el desconcierto que produjo el creciente rezago electoral y la distorsión persistente de la imagen pública del candidato demócrata, en el momento de los hechos. Para ello, pretendemos ligar la coyuntura con las tendencias estructurales de la cultura política norteamericana.

Con este propósito, empezamos por analizar los antecedentes inmediatos al socavamiento del liberalismo llevado a cabo por el neoconservadurismo reaganiano. A continuación examinamos las elecciones de 1988 a través de la función de la "ideología" y de la "eficiencia" en la doble lógica electoral (presidencial y legislativa), y nos referimos a la construcción y efectos de la imagen política de los candidatos presidenciales, así como a las proyecciones actuales del liberalismo demócrata. Después, ahondamos en los condicionantes estructurales de esta coyuntura a través del quiebre ideológico, cultural y político del consenso liberal rooseveltiano, para concluir con una breve alusión a la "L-word" en la que se sintetiza la estigmatización del liberalismo en 1988.

\section{Embate reaganiano contra el liberalismo}

El liberalismo ${ }^{1}$ ha experimentado, en Estados Unidos, un desgaste retórico innegable. Es sorprendente que haya pasado a ser una

1 Creemos importante explicar la connotación de liberalismo que empleamos en el presente artículo, debido a su carácter particular. El término ha experimentado importantes transformaciones semánticas, a lo largo de la historia del pensamiento político y económico norteamericano. Actualmente, difiere de la acepción clásica del siglo XVIII, en su conceptualización de lo económico. Si bien el modelo capitalista sigue vigente, el laissez-faire ha sido sustituido por la tendencia a adoptar políticas proteccionistas y de intervención del gobierno en la economía y la sociedad. Este es el liberalismo económico de cuño rooseveltiano que surgió con el New Deal y que incrementó el poder gubernamental para hacer frente a los efectos de la Gran Depresión iniciada en 1929. El ejecutivo aplicó regulaciones a la industria y al comercio, a la vez que instituyó programas extensivos de bienestar social. Esto le ha valido los calificativos de intervencionista y de populista respecto a la economía. En oposición, el conservadurismo norteamericano actual, sí es de matriz liberal clásica, debido a su 
"mala palabra", cuando el sistema político norteamericano surgió como una encarnación quasi perfecta y exaltada del modelo liberal. ${ }^{2} \mathrm{Si}$ bien su desarticulación y su desprestigio han tenido diversas causas en el tiempo, ${ }^{3}$ su ruptura puede asociarse al surgimiento de la revolución reaganiana y a los cambios que ésta imprimió a la política.

Reagan basó su legitimidad en el cuestionamiento del big government (Estado regulador) y en el apoyo a una amplia coalición política constituida por votantes de clase media que quieren impuestos bajos, intereses económicos que se pronuncian por un ámbito empresarial libre, conservadores religiosos que se oponen al activismo crítico, neoconservadores que presionan por una política exterior más agresiva, y votantes con temores y resentimientos raciales. Para estos grupos, liberalismo significa elevación de impuestos, regulaciones y proteccionismo gubernamental, cuestionamiento de los valores norteamericanos tradicionales, defenisa nacional débil e inconsistente, al igual que protección a los intereses de los negros y promoción de los derechos civiles.

Reagan logró sintetizar, expresar y ahondar el malestar general frente a políticas sociales y económicas identificadas con la gestión, de casi medio siglo, del Estado liberal benefactor. Tal es el caso de los programas de asistencia social de la "Guerra contra la pobreza" y la prioridad de los derechos civiles, que generaron un resentimiento creciente de las clases media y obrera por el otorgamiento de derechos y beneficios a los pobres, las minorías, las mujeres y otros grupos en desventaja que requieren por lo mismo atención especial, beneficios que se traducían en la elevación de la carga impositiva y en la expansión de la burocracia gubernamental. Así, la clase media - la más castigada con la carga impositiva - llegó a concebir a la elite liberal como una dirigencia con discurso de izquierda, que vivía como de derecha y que hacía pagar a la mayoría trabajadora. El descontento aumentó en la década de los setenta con los efectos de la crisis inflacionaria y los altos niveles de desempleo, así como con lo que se consideró el debilitamiento de la hegemonía internacional de Estados Unidos después de la guerra de Vietnam y del secuestro de rehenes estadunidenses en Irán.

defensa reiterada del laissez-faire económico. En lo político, el liberalismo norteamericano de nuestros días continúa basando la democracia en los principios clásicos de libertad, tolerancia y derechos individuales. Lo que ha cambiado con el tiempo, han sido las instituciones y prácticas de legitimación que sustentan su sistema político.

2 Sobre liberalismo hoy en Estados Unidos, véanse Lou is Hartz, The Liberal Tra dition in America, New York, Harcourt Brace Jovanovitch Publisher, 1983; Alan Wolfe, Los limites de la legitimidad: las contradicciones políticas del capitalismo contemporáneo, Siglo XXI Ed. México, 1980. Carlos Rico, "Las dimensiones de la crisis política norteamericana y sus perspectivas en los años ochenta: una revisión de la literatura", en Cuadernos Semestrales. Estados Unidos: perspectiva latinoamericana, núm. 14, México, CIDE, $2^{\circ}$ semestre de 1983; Charles Peters, "Manifiesto del Nuevo Liberalismo", op. cit.

S Las causas más importantes del resquebrajamiento del modelo liberal son: reformulaciones y cuestionamientos al keynesianismo; relectura ideologizada de los problemas de los gobiernos liberales de los sesenta y setenta; resquebrajamiento de la cultura estadunidense, a través de la rebelión primero, contra la autoridad y después, contra la modernidad; y desmembramiento de los soportes que legitimaban al sistema político, en concreto, la identidad nacional generada a partir del New Deal y, posteriormente, del "Estado neutral". Estos temas serán retomados en el último inciso de este artículo. 
En este contexto, Reagan apareció como la alternativa por su programa antigubernamental de reducciones impositivas y de libre mercado, y como salvador del pueblo porque contribuyó a/o coincidió con la recuperación económica de los últimos seis años; proyectó una imagen de fortaleza en el liderazgo internacional y contuvo así la amenaza liberal. En concreto, el gobierno reaganiano puso en práctica recortes o eliminación de programas sociales y de bienestar para los pobres; la disminución de los impuestos en especial, para los sectores de más altos ingresos; la reducción de las regulaciones gubernamentales sobre el comercio y la industria, y el incremento del presupuesto militar. Por otra parte, en política exterior pasó de posiciones de enfrentamiento -ante aquellos países que podían amenazar su seguridad- a medidas de distensión, hacia el final de su segundo mandato.

Sin embargo, el balance de la herencia de Reagan no es del todo favorable. Si bien creó 18 millones de nuevos empleos, disminuyó la inflación, mantuvo el crecimiento sostenido y redujo el desempleo por debajo de 6\%; también hizo que Estados Unidos pasara de ser una nación acreedora a ser una nación deudora (la posición internacional de su inversión neta cambió, de tener un superávit de 106 mil millones de dólares en 1980 a tener un déficit de más de $400 \mathrm{mil} \mathrm{mi-}$ llones en 1988).

Es de esperarse que, tarde o temprano, los 75 meses de expansión económica que contribuyeron a que el electorado votara por la continuidad y contra el liberalismo, en 1988, se derrumben frente a la realidad de los déficit gemelos y la deuda. Una somera aproximación a los indicadores económicos de este país, demuestra que su situación actual es difícil en los renglones presupuestal, productivo, comercial y monetario. ${ }^{4}$

De aquí se podría concluir que el mayor triunfo de la revolución reaganiana haya sido ideológico. Reagan fue un oficiante de los símbolos públicos. Revivió las imágenes míticas del pasado de "América" y con ellas alimentó la esperanza en un futuro liberado de los efectos traumáticos de la década de los sesenta y setenta. Restauró el optimismo y la moral de los norteamericanos, así como su fe en el liderazgo y la institución presidencial. La amenaza del big government (Estado regulador) causante de los desequilibrios del sistema, la enfrentó. de hecho con el big business (gran empresa) como alternativa de reconstrucción nacional. ${ }^{5}$

Lo que está en el fondo de la confrontación entre los modelos liberal y reaganiano es su diferente concepción del Estado. Para el primero es una institución política necesaria, mientras que, para el segundo, es una instancia administrativa susceptible de ser reducida a su mínima expresión y, por tanto, debilitada. Veamos sus referentes históricos contemporáneos.

La coalición rooseveltiana se constituyó con base en las demandas hechas al gobierno de combatir los efectos devastadores de la Gran Depresión y de reorganizar a la nación. En oposición, medio siglo después, la coalición de Reagan surgió como la concertación

- Véase Ronald Dellums, "La era de Reagan", en Perfil de la Jornada, 20 de enero de 1989.

3 Lance Morrow, "A Change in the Weather", ensayo, Time, 30 de marzo de 1987. 
de demandas antigobiernistas orientadas a restringir las funciones del gobierno, identificado como el responsable último del proceso de inflación sostenida de los setenta. Ambas coaliciones representan diferentes vivencias sobre la política. La primera corresponde a la generación posterior a la primera Guerra Mundial, que vio en el Estado regulador del New Deal a su protector y experimentó los beneficios del gasto público (en seguridad social, viviendas, etc.). La segunda generación, posterior a la segunda Guerra Mundial, (la de los baby boomers) vio a ese tipo de gobierno como una amenaza que la convirtió en pagadora de impuestos y la excluyó de sus beneficios. En realidad, son dos generaciones que vivieron, respectivamente, el auge y la crisis de los gobiernos liberales de este siglo. ${ }^{6}$

Con la nominación republicana de George Bush a la presidencia se temió que la coalición reaganiana se desintegrara. Esta se había conformado en torno al liderazgo carismático del presidente saliente, cuyo mesianismo político, económico y axiológico estaba fuertemente apoyado en una promesa implícita de salvación. Bush no posee estos atributos y, sin embargo, la coalición se mantuvo: $85 \%$ de los que estuvieron conformes con el mandato de Reagan votaron por Bush y por la continuidad de la política económica y social.

Además de la promesa de seguir con la expansión económica, la propuesta política reaganiana, en cuanto a considerar a los liberales una amenaza, fue refrendada por George Bush que, entre otras cosas, logró imprimir también un cariz negativo a la opción liberal estigmatizándola como el mal para la república.

El tema de liberalismo y del ser liberal permeó el proceso electoral a la presidencia de Estados Unidos de 1988. En él se cuestionó y se desacreditó al liberalismo como filosofía política y como programa de gobierno, a la vez que recibió un manejo publicitario que cristalizó en ese estigma que Bush concretó en Dukakis y que éste no supo ni pudo enfrentar.

\section{"Ideología" y "eficiencia" en las dos lógicas electorales}

La derrota demócrata fue contundente en números absolutos en las elecciones presidenciales de 1988. Michael Dukakis obtuvo 112 votos electorales de un total de 538 y $46 \%$ del voto popular. No obstante, un análisis minucioso de los resultados revela un avance demócrata en términos relativos $(750 \%$ sobre Walter Mondale en el Colegio electoral en 1984 y el porcentaje más alto de apoyo ciudadano alcanzado por los perdedores desde 1964) y triunfos incuestionables en los Congresos federal y estatal, así como la obtención de una gubernatura más. ${ }^{7}$ En esta ocasión, los norteamericanos emitie-

\footnotetext{
6 Mortimer B. Zuckerman, "Old liberalism, New politics" en U.S. News \& World Report de 7 de noviembre de 1988.

7 No hay duda de la importancia del Congreso y de los estados en un sistema político definido por las relaciones de equilibrio - pesos y contrapesos- entre los poderes ejecutivo, legislativo y judicial. Sin embargo, el significado político de la presidencia, como cargo de representación máxima e instancia donde se ejerce la dirección interna y externa de la nación, la hace ser el objetivo superior -aunque no el único- de las fuerzas políticas. Sobre sistema político norteamericano, véanse Anthony King, The New American Political System, Washington, AEJ, 1983; James $\mathrm{Q}$ Wilson, American Government, Health and Co., Lexington Massachusetts, 1987.
} 
ron un voto dividido y apoyaron a los republicanos para la presidencia y a los demócratas para el Congreso. De esta manera, exigieron la negociación y el compromiso de las principales fuerzas políticas a nivel nacional. ${ }^{8}$

Una vez concluido el proceso electoral, los medios de comunicación se abocaron a recrear ampliamente la legitimidad del triunfo de George Bush. En contraposición, los analistas dieron explicaciones diversas y de alto contenido polémico sobre el fracaso de $\mathrm{Mi}$ chael Dukakis. Hicieron alusión a los problemas de dirección y organización de la campaña, al triunfo de la continuidad sobre las propuestas de cambio y a la falta de consenso en torno a medidas liberales. ${ }^{9}$ No obstante, cabría mencionar otra explicación de tipo estructural que alude a la doble lógica electoral estadunidense: la carrera presidencial y la contienda legislativa.

En la lógica presidencial tiene un peso determinante la conducción de la "ideología" en las campañas. Cabe aclarar que, para los estadunidenses, el término ideología es una representación del mundo asociada indisolublemente con la confrontación política de ideas. Esta desempeña un papel importante en la carrera electoral a la presidencia, porque contribuye a un proceso de exclusión de candidatos donde nada más uno accederá al cargo y detentará el poder. Este poder no se comparte, sólo se delegan responsabilidades, en contraposición a lo que sucede en el legislativo. Sin embargo, después de la confrontación de las campañas y del veredicto de triunfo o fracaso en las elecciones, deberá seguise la concertación como práctica de gobierno.

El liderazgo presidencial se apoya, entre otros recursos, en proyecciones carismáticas individuales $\mathrm{y} / \mathrm{o}$ institucionales y en representaciones colectivas que proporcionan efectos de seguridad y confianza en la conducción nacional. Su legitimidad se fragua a partir de los orígenes, tradiciones y valores genuinamente norteamericanos, que son transmitidos a través de ideologías con gran capacidad de interpelación. Es decir, se busca producir un efecto de reconocimiento en los ciudadanos para lograr un consenso básico, además de proyectar el contenido político del liderazgo presidencial antes de su puesta en práctica.

En la lógica legislativa pasa a ser determinante la "eficiencia" de los candidatos. Estos tratan de garantizar eficacia para satisfacer las demandas de los habitantes de su circunscripción, y poder así ser reelectos constantemente. Se ha comprobado que el apoyo de los votantes se incrementa si el postulante ha demostrado su capacidad en gestiones anteriores.

Tal parece ser que un error de apreciación y estrategia de la campaña de Michael Dukakis fue privilegiar la "eficiencia" sobre la "ideología", como si aspirara a una senaduría o gubernatura. Esto obedeció, en parte, a su calidad de demócrata moderado y pragmático que antepone la dirección tecnocrática al activismo político. Dukakis ofreció eficiencia a la clase media y a los trabajadores en un momento en que disfrutaban de la expansión económica. Los

B Estados Unidos: Perspectiva latinoamericana, Carta Mensual, México, IEEU. CIDE. diciembre de 1988.

9 William Schneider, "Tough Liberals Win, Weak Liberals Lose". en 7 he New Republic, 5 de diciembre de 1988. 
norteamericanos no demandaban eficiencia, habia eficiencia. Por eso, cuando Bush prometió prosperidad, satisfizo el deseo de la mayoría de que continuara la recuperación económica. De igual manera, Dukakis no entendió el distinto poder de los temas sociales y axiológicos en el norteamericano. Su posición progresista frente al crimen y pragmática frente al juramento a la bandera, generó dudas sobre la fortaleza de su posible mandato presidencial y de su patriotismo, así como escepticismo sus propuestas sobre política exterior.

De otra parte, pudo haber perjudicado a Dukakis la tendencia de la opinión pública a identificar a los demócratas con el Congreso, debido a que en cinco de las últimas seis elecciones han perdido la presidencia manteniendo la hegemonía en el Congreso. Cada vez más, se concibe a los demócratas como congresistas apasionados que cumplen con su misión de limitar al poder presidencial y poner en práctica las medidas políticas.

La situación política de los demócratas puede encontrar una de sus explicaciones profundas en la crisis de identidad programática e ideológica que cobró fuerza a partir de 1980. En términos prácticos, esgrimir la causa liberal era perder a los blancos del sur y no hacerlo era debilitar su presencia entre las minorías étnicas y grupos en desventaja. En 1988, los demócratas de centro optaron por el pragmatismo. Pero los resultados del 8 de noviembre evidenciaron el fracaso de su estrategia, ya que no lograron atraer a los sureños conservadores ni aumentar su influencia entre las minorías.

Esta derrota tiene, además, otras explicaciones. Una de ellas está en la naturaleza del Partido Demócrata, marcado por profundas diferencias que se manifiestan en la composición social de sus militantes y simpatizantes, así como en su praxis política e ideológica. En el proceso electoral que nos ocupa, las tres grandes corrientes, moderados, derecha e izquierda, estuvieron representadas por Dukakis, Bentsen y Jackson, respectivamente. ${ }^{10}$ Con la fórmula DukakisBentsen se forjó una poderosa coalición tecnócrata. Su denominador común fue el pragmatismo, que tiene su principio en el "realismo" político (realpolitik) que hace que percepciones diferentes se identifiquen por los resultados. De aquí que la nueva coalición haya privilegiado el savoir-faire - la tecnología- de la política frente a la razón del ideario político. En consecuencia, durante la mayor parte de la campaña, la corriente jacksoniana fue excluida y la unidad del partido quedó desarticulada. Puede apreciarse cómo

10 En Estados Unidos - aún más que en otros países-, resulta esquemático definir a los políticos como moderados, de derecha o de izquierda. De hecho estos términos tienen un uso metodológico para ilustrar grandes tendencias y sirven para hacer comparaciones generales. El National Journal, de 28 de enero de 1989, define ideológicamente a los legisladores norteamericanos de acuerdo con la orientación de sus votos en asuntos económicos, sociales y de política exterior. Los clasifica en: a) liberales, si su voto fue consistentemente liberal en los tres temas; $b$ ) conservadores, si su voto fue reiteradamente conservador en los tres asuntos; $c$ ) populistas, si su voto fue predominantemente liberal en temas económicos y conservador en asuntos sociales y de política exterior; y $d$ ) libertarios, si su voto fue mayoritariamente conservador en cuestiones económicas y liberal en temas sociales o de política exterior. Por ejemplo, Lloyd Bentsen de Texas, el candidato demócrata a la vicepresidencia en 1988, fue definido como "centrista" en el amplio espectro político de Estados Unidos, porque su voto fue mitad liberal y mitad conservador en los tres temas. En el ámbito del Partido Demócrata, que está a la izquierda del electorado, Bentsen es asociado con el ala derecha. Se pensó que reunía las características para atraer el voto de los demócratas reaganianos del Sur que, según la clasificación arriba descrita, son populistas. 
el amplio espectro político del Partido Demócrata, le ha dificultado proyectar una imagen nacional coherente, con perfil definido; ya que la unión de los extremos - Jackson-Bentsen- hubiera resultado inaceptable para las bases electorales de cada uno.

En la Convención Demócrata de 1988, Jesse Jackson desempeñó el papel de ideólogo. En su discurso renacieron las tradiciones, ideales y valores del Partido Demócrata. Jackson sumergió a los presentes en una mística liberal y los hizo partícipes de una suerte de comunión política. No obstante, a la hora de la votación, la mayoría se pronunció a favor del pragmatismo. Tal parecería que el fenómeno Jackson cumplió la función de provocar la catarsis colectiva y el rito de autentificación, que después terminó subordinándose al espíritu práctico norteamericano. Pero este movimiento también reveló signos políticos y culturales interesantes, que probablemente harán sentir sus efectos organizativos y de fuerza en un futuro no muy lejano.

Durante la mayor parte de la campaña, la consigna de la "eficiencia" se tradujo en una plataforma neutral, vacía de aquellas significaciones de la cultura política estadunidense necesarias para producir la identificación del votante con el partido. Asimismo, se desarrolló una campaña parca y. tímida. Sólo en las últimas tres semanas de la contienda electoral se esgrimió la identidad liberal con pasión y orgullo, dotando a la campaña de un espíritu de compromiso y agresividad.

El fracaso electoral dividió aún más a los demócratas. La corriente jacksoniana declaró que los moderados habían perdido su oportunidad y que esperaban que la próxima ocasión hubiera un candidato "demócrata verdadero", en el sentido liberal. La derecha consideró que había habido un insuficiente viraje del partido a la derecha e interpretaron el cariz ideológico de los últimos días de la campaña como una debilidad que debería erradicarse. Por tanto, la derrota de los moderados trascendió el proceso electoral y dejó sin mediación a dos fuerzas polares del partido. La situación es políticamente delicada porque ni el dogmatismo liberal ni su negación absoluta contribuirán, seguramente, a reafirmar la identidad demócrata.

\section{Imagen política de los candidatos presidenciales}

La proyección de la imagen pública de los candidatos es determinante para el proceso de reconocimiento de la ciudadanía de los valores y estrategias políticas simbolizadas por cada uno. En politica, las imágenes se crean y, particularmente en Estados Unidos, adquieren la función de mercancias que se comercializan a través de los más sofisticados métodos publicitarios. En este país, la política tiene una fuerte dimensión mercadotécnica. ${ }^{11}$

La imagen de George Bush no ha sido difícil de definir. Es anglosajón, miembro del establishment del Este por nacimiento, pero identificado con el Sur debido a que vivió largo tiempo en Texas. Proviene de familia adinerada y se ha desempeñado exitosamente

1 Véase Newsweek, núm. 47, 21 de noviembre de 1988. Número dedicado a las campañas presidenciales de 1988 en EU, en el que se atribuye gran importancia a la publicidad política. 
como empresario. Fue reconocido como valeroso combatiente del Pacífico durante la segunda Guerra Mundial. Como funcionario de primer orden (en la ONU, la CIA, en China y la vicepresidencia de EU) permaneció a la sombra de sus superiores, y en el espectro político republicano se le puede identificar como conservador pragmático de centro. En suma, es el WASP "ideal", lo cual no tiene que ver con la bondad o maldad de sus propuestas políticas.

Michael Dukakis representa a los nuevos estadunidenses, inmigrantes de segunda y tercera generaciones, que contribuyeron al milagro norteamericano. Es de los demócratas que se iniciaron en la política con los movimientos por los derechos civiles y contra la guerra, y que permanecieron leales a esos valores, pero que han protagonizado un nuevo estilo tecnocrático de política. Proviene del Este, donde la tradición liberal rooseveltiana es intensa, y en el espectro político demócrata ocupa una posición de liberal pragmático de centro.

No obstante, en el inicio de las campañas presidenciales de 1988 , la imagen de Bush se había modificado en términos negativos por su vinculación con la toma de decisiones políticamente cuestionadas o desautorizadas por el Congreso. Como vicepresidente mantuvo vínculos con Ferdinand Marcos, promotor de un régimen autoritario en Filipinas; en varias ocasiones se entrevistó con Noriega de Panamá, después de que se denunciaron sus nexos con el narcotráfico y, en cierta medida, fue considerado responsable del Irán-contras en su calidad de vicepresidente. Por último, escogió como compañero de fórmula electoral a Dan Quayle, quien no convenció a la opinión pública acerca de su capacidad para dirigir a la nación en caso de que él faltara. En contraposición, Dukakis contaba con una imagen positiva. Su gestión como gobernador de Massachusetts era reconocida por sus aciertos políticos y administrativos. Como candidato proyectó un mensaje ideológicamente neutro y un perfil tecnócrata acorde con su reiterada consigna de eficiencia.

Se llegó a pensar que estas dos imágenes políticas se polarizarían aún más en detrimento de los republicanos, con el manejo publicitario que se dio al escándalo Irán-contras. La televisión nacional puso en evidencia a un gobierno que pasó por encima del Congreso, manteniendo actividades militares y paramilitares encubiertas en todo el mundo. Fueron acciones en contra del carácter democrático del sistema político norteamericano, que se funda en el equilibrio de poderes. El ejecutivo se dio atribuciones inconstitucionales; no obstante, hasta noviembre de 1988 su cuestionamiento se habia limitado a la discusión en torno a las razones del coronel Oliver North y sus colegas para no informar de sus actividades a los miembros del Congreso.

El Irán-contras puso en duda la razón de Estado y la legitimidad del gobierno reaganiano. ${ }^{12}$ Sin embargo, su impacto negativo en la ciudadanía se vio superado apenas un año después, si consideramos que cuando Reagan dejó la presidencia contaba con un altísimo nivel de popularidad. El gobierno ha sido extremadamente cuidadoso en la conducción de este conflicto, ya que el sistema político

12 Véase Pedro Javier González, "De la racionalidad y la legitimidad: una lectura del Irangate", en Cuadernos Semestrales, Estados Unidos: Perspectiva Latinoamericana, núm. 21, México, CIDE, primer sermestre de 1987. 
norteamericano difícilmente resistiría otra crisis de constitucionalidad, veinte años después de Watergate.

Este contexto y el desinterés del público por los asuntos del Programa de Seguridad Nacional de Reagan, favorecieron la estrategia publicitaria del equipo republicano dirigido por Roger Ailes, que consistió en cambiar la imagen de Bush y desprestigiar a su oponente. Se dieron a la tarea de moldear la ideología amorfa de Dukakis, dotándola de un contenido inaceptable. Bush satanizó a su contrincante con el epíteto de "liberal de Massachusetts" y "suave frente al comunismo".

Dukakis se vio atrapado en una paradoja que no supo ni pudo superar. Ante los límites del modelo liberal y del gobierno positivo, en un periodo de crisis económica y de recomposición de la hegemonía internacional, quiso deslindarse de la ideología histórica demócrata con todas sus connotaciones populistas, para identificarse como moderado, pragmático y tecnócrata eficiente a favor de un good government (buen sistema de gobierno). Sin embargo, sus esfuerzos se vinieron abajo de la noche a la mañana, cuando la opinión pública aceptó y creyó en la "etiqueta" que le "colgó" Bush.

En un principio, Dukakis pensó que la táctica republicana sería identificada como de guerra sucia y que se volvería en contra de Bush, autodescalificándolo. En un segundo momento, cuando advirtió que ya se le había "etiquetado" definitivamente en tanto que liberal, quiso contraponer los mismos argumentos que había esgrimido al inicio de su campaña y que ya habían demostrado su falta de eficacia. Y, por último, cuando tomó conciencia de que no podría liberarse de esta etiqueta, se definió públicamente como un liberal de la tradición de Franklin D. Roosevelt, Harry Truman y John F. Kennedy. Esta estrategia fue positiva pero tardía, además de que fue parcialmente neutratizada por Bush, cuando afirmó que, en realidad, Dukakis era un liberal de la tradición de George McGovern, Jimmy Carter y Walter Mondale. La imagen liberal despectiva ya había sido exitosamente interiorizada por la opinión pública.

El estigma liberal cumplió, sin embargo, una función importante inesperada. Diferenció a dos candidatos que tenían muchos aspectos coincidentes: ambos son identificados como moderados, pragmáticos y de centro en sus respectivos partidos políticos; y ambos coinciden en una aproximación a los problemas internos y externos de Estados Unidos, fundada en el "realismo" político y económico, y viabilizada a través de la negociación. Sus diferencias están en el cómo. Son, entonces, candidatos de centro pero ante una ciudadanía que ha experimentado un corrimiento de su centro hacia la derecha. Esto, necesariamente, favoreció a las ideologías conservadoras y al candidato republicano.

Para profundizar las diferencias entre centro progresista y centro derecha, Bush esgrimió el lastre místico fiberal contra Dukakis asociándolo con todo aquello que, por su pragmatismo, les resulta inaceptable a los norteamericanos hoy. Y produjo el efecto de verdad deseado. Un sector importante de la ciudadanía lo creyó defensor a ultranza del expansionismo e intervencionismo gubernamental en la economía y en la sociedad; lo representó como débil frente al crimen, suave ante el comunismo e inconsistente en su patriotismo. Sin embargo, un análisis sistemático e imparcial de la trayectoria y 
las convicciones de Michael Dukakis desmentiría, en mucho, esta imagen.

La formulación de este estigma se dio cambiando la significación clásica de lo liberal para adaptarla a la mentalidad del votante por medio de una cadena de identificaciones axiológicas negativas que operaran inconscientemente en grandes e importantes sectores de norteamericanos. Estas podrían expresarse de la siguiente manera: Ser liberal es igual a ser antipatriota (Dukakis propuso el rechazo al juramento a la bandera en las escuelas) y equivale a no ser un verdadero estadunidense (Dukakis es hijo de inmigrantes griegos); debilidad en la defensa nacional y frente al crimen (Dukakis pedía la reducción al presupuesto militar y estaba el caso William Horton); ${ }^{13}$ es sinónimo de relajamiento de los valores tradicionales de Norteamérica (Dukakis es miembro de la Unión Americana de Libertades Civiles, ACLU) ${ }^{14}$ y, por tanto, es una amenaza para la república. Ante tales planteamientos resulta lógico que los norteamericanos rechazaran el riesgo liberal en 1988; la maniobra de los republicanos funcionó. En una encuesta de octubre, una mayoría simple de ciudadanos identificó a Dukakis como liberal, siendo que tan sólo tres meses antes la proporción era de un tercio. Esto se relaciona con una pérdicia considerable de popularidad, que descendió de $75 \%$ a $50 \%$ de julio a octubre, según otra encuesta de la $N B C$ News-Wall Street Journal.

La estrategia publicitaria del Partido Republicano correspondió en términos más generales a las percepciones, vivencias y deseos de los norteamericanos. Frente a la disyuntiva de paz y prosperidad versus crisis y cambio, optaron por la primera. Esto es, debido a que la contracción económica no ha afectado seriamente al presupuesto de la mayoria de las familias, se pronunciaron por la continuidad en lá recuperación e ignoraron los augurios de tiempos difíciles. De hecho, Dukakis transmitió un mensaje pesimista a través de temas tales como el estrangulamiento de la clase media y la inminencia de decisiones difíciles que él estaba preparado para ejecutar y Bush no. Contrariamente, Bush fue portador del optimismo al asegurar que todo estaba bien y que la expansión económica seguiría. La lectura subliminal de la opinión pública fue la equiparación de pesimismo

is El caso William Horton fue un ejemplo de manipulación ideológica que produjo gran indignación entre los demócratas. Horton es un homicida negro quien al estar de licencia de fin de semana, escapó y asaltó y violó a una pareja blanca de Maryland. Este hecho fue indirectamente publicitado por Bush y su equipo de campaña, impugnando el régimen de libertad provisional de Massachusetts bajo la gubernatura de Dukakis. Esta legislación fue obra de su predecesor republicano y ha sido formulada y aprobada con variaciones, en buen número de los estados de la nación norteamericana. Grupos de republicanos dotaron al caso Horton de un cariz racista y Bush lo manejó como una prueba de la debilidad del candidato demócrata frente al crimen.

14 Además del caso Willie Horton y del veto de Dukakis a la iniciativa del Congreso de Massachusetts, de hacer obligatorio el juramento a la bandera en las escuelas, George Bush argumentó la identidad liberal de su oponente demócrata dando a conocer su membresía en la Unión Americana de Libertades Civiles (ACLU). Esta Asociación ha sido definida como liberal de izquierda por su activismo, primero contra la guerra de Vietnam y después contra la política de Estados Unidos hacia Centroamérica; asi como por sus demandas de legalizar el consumo de todo tipo de drogas y de no penalizar la distribución de pornografía, incluyendo la infantil. Lo que para la ACLU significa defensa amplia de las libertades civiles y los derechos individuales, para los neoconservadores es signo de la decadencia de los valores tradicionales de Norteamérica: morales y religiosos. 
con falta de confianza en Norteamérica e inseguridad; asimismo, identificó optimismo con confianza en el destino de Estados Unidos y seguridad. De esta manera, se impuso el optimismo.

Dukakis ofreció a la clase media y a los trabajadores programas autofinanciables, tales como apoyo a colegiaturas de universitarios, guarderías, seguros médicos para empleados, hipotecas sobre viviendas, etc. Sin embargo, la suspicacia del público frente a estas promesas fue fuerte. Por otra parte, Bush ofreció resolver las dificultades económicas de los sectores medios manteniendo la recuperación implantada por Reagan. Bush se basó en logros para ofrecer continuidad; de esta manera, el republicano revistió sus argumentos de realismo, mientras que las promesas programáticas del demócrata parecieron utópicas y se consideró que su operatividad recaería, tarde o temprano, en los contribuyentes. Es así como el estigma liberal operó como una fatalidad.

\section{Perspectivas de liberalismo demócrata}

El proceso electoral que culminó el 8 de noviembre de 1988 con el triunfo de George Bush, demostró que la consigna liberal, lejos de atraer a los votantes a favor de los demócratas, descalificó a Michael Dukakis y movilizó a parte del electorado en su contra, porque fue constituida en un estigma. Ahora, si bien es cierto que el significado de la "L-word" (la señal-L) - el vocablo innombrable-, fue ventajosamente manipulado, capitalizado y dotado de negatividad por Bush y Reagan, también es cierto que esto fue factible por las dificultades que han tenido los liberales para redefinir el término, para articular un proyecto nacional, para movilizar a amplios sectores de la sociedad -entre ellos a los grupos desfavorecidos por la "reaganomics" - y para reconstituir una coalición estable. ${ }^{15}$

Los analistas políticos señalan que los demócratas han perdido las elecciones nacionales cuando los temas sociales, axiológicos, de tolerancia y de política exterior han dominado las instancias de discusión política. Estos temas dividen a los demócratas porque no son negociables, ya que se consideran principios morales (el aborto, por ejemplo), y en ellos la dirigencia partidaria está a la izquierda de sus bases. Según su apreciación, el tema de las campañas tendría que ser el populismo económico en el que las bases están a la izquierda de sus dirigencia. Sin embargo, en los últimos 30 años el proceso demócrata de selección de candidatos a la presidencia ha privilegiado a hombres progresistas en política social y exterior, e insuficientemente definidos en política económica. ${ }^{16}$

${ }^{15}$ La quiebra del consenso liberal rooseveltiano y el desmembramiento de la coalición que lo sustentaba, debilitó considerablemente al liberalismo demócrata. Acerca de la construcción del consenso rooseveltiano, véase Richard, Hofstadter, La tradición política norteamericana, México, FCE, 1984, cap. XII. Y sobre los resultados históricos del modelo del rooseveltiano, véanse José Miguel Insulza, "Estados Unidos: de Roosevelt y Reagan", Grandes tendencias politicas contemporáneas, núm. 12, México, UNAM, 1986; Atilio Borón, y Víctor Godínez, "Entre Roosevelt y Reagan: contenidos y límites de la alternativa neoliberal" en Cuadernos Semestrales, Estados Unidos: perspectiva latinoamericana, núm. 14, México, CIDE, segundo semestre de 1983.

16 Robert Kuttner, "The Incompetent Ideology" en The New Republic, 5 de diciembre de 1988. Véase su libro The Life of the Party, 1987. 
Vemos que sólo hacia el final del proceso electoral de 1988, la contienda se llegó a definir en términos de populismo económico versus populismo social; es decir, la estrategia de confrontar a las clases versus la defensa de los valores y tradiciones norteamericanas. Dukakis recurrió al populismo económico para unificar a las bases del Partido Demócrata, conformadas predominantemente por liberales blancos y negros (los contingentes de Dukakis y Jackson), caracterizados por profundas divergencias. El $80 \%$ de los negros y $63 \%$ de los hispanos votaron por el Partido Demócrata. La capacidad de convocatoria del populismo social de Bush fue mayor y cubrió un amplio espectro de votantes: $55 \%$ de las clases medias, $53 \%$ de los baby boomers, $52 \%$ de los católicos y la mayoría de los jóvenes de 25 a. 28 años, entre otros.

Los demócratas están ante una encrucijada. Volver al liberalismo rooseveltiano sería tanto como desconocer la existencia de un modelo económico y de coaliciones políticas diferentes. Pero negar el liberalismo sería tanto como desconocer los orígenes de su identidad histórica y confundirse con la opción conservadora del Partido Republicano. Y por último, otorgarle un nuevo significado al término sin un proyecto nacional coherente y alternativo, podría desembocar en la ambigüedad y en la indefinición política. Planteado así el problema, la solución se revela difícil y a largo plazo.

Parecería, por tanto, que estaba descartada una estrategia para "liberalizar" a los liberales — con la subsecuente polarización de fuerzas en el espectro político norteamericano- consistente en declarar inexistente todo lo relacionado con la "L-word", con el esúgma; pues, mientras no se constituya un nuevo consenso liberal que actualice el pensamiento referente a las necesidades económicas, políticas y sociales de los estadunidenses y que se presente como una opción de cambio adecuada a lo objetiva y subjetivamente demandado a nivel nacional, los demócratas podrán seguir ofreciendo candidatos y opciones aceptables tanto para los liberales como para otros sectores de la sociedad. En consecuencia, podrían armar un programa de consenso que ni excluyera ni negara lo liberal, sino que lo contuviera y articulara en sus puntos de coincidencia con otras posiciones representativas. No obstante, esta sería una alternativa uansitoria, conservadora, para ampliar su capacidad de convocatoria entre la ciudadanía.

\section{Acerca de la ruptura ideológica, cultural y polf́tica del consenso liberal}

Más allá del análisis de coyuntura sobre el proceso electoral de 1988 en Estados Unidos, podríamos afirmar que el liberalismo como filosofía política continủa permeando los consensos básicos de la sociedad norteamericana. Tanto demócratas como republicanos suscriben en términos generales el laissez-faire, la libertad política y religiosa, el Estado representativo, así como la necesidad de algún tipo de acción gubernamental. Las diferencias se expresan en las modalidades y límites que adquieren estos principios en los proyertos nacionales y en los programas de gobierno sustentados por cada partido.

El caso de la intervención del gobierno en la economía y en la sociedad es ilustrativo. En las campañas electorales de 1988 hubo 
pronunciamientos de ambos extremos del espectro político sobre cómo orientar el gasto público. Los republicanos se manifestaron a favor del gasto en seguridad social, subsidios a la industria y proyectos hidráulicos, entre otros. Por su parte, los demócratas vieron con beneplácito el gasto en bonos de alimentos y subsidios a los granjeros, así como la formulación de tarifas comerciales. ${ }^{17}$

Esta investigación gana en profundidad si se parte de la realpolitik, donde la clase política se ve enfrentada a situaciones y alternativas que precisan de modificar en la práctica su declaración de principios. No hay duda de que, vista así, la política es el arte de lo factible. De aquí que podamos ver, por ejemplo, a un conservador elevando impuestos y a un liberal eliminando restricciones a la industria.

Entonces, ¿cuál es el origen de la sospecha actual frente al liberạlismo y del descrédito de los liberales? ¿Por qué siendo la nación norteamericana hija del liberalismo, hoy en día sólo el $15 \%$ de sus ciudadanos se declara liberal ${ }^{18} \mathrm{~A}$ continuación ensayamos tres respuestas a estos problemas, bajo las perspectivas ideológica, cultural y política.

Todavía está viva la memoria colectiva de los fracasos de los gobiernos liberales en los 60 y los 70 . Dicha experiencia produjo un resentimiento generalizado contra Washington, el gobierno regulador y la consiguiente concentración del poder en manos de los burócratas; es por esto que ambos fueron tachados de males del liberalismo y no operacionales. A partir de ello se articuló una ideología que achacó a los demócratas liberales actos perversos de voluntad política que habrian generado los desequilibrios de fines de los $70 \mathrm{e}$ inicios de los 80: los altos niveles de inflación y desempleo, las limitaciones a la competencia empresarial, las burocracias sindicales corruptas, los privilegios a ancianos y pobres en los sistemas de seguridad y asistencia social a costa de una política impositiva desproporcionada para las clases medias y los trabajadores, el abuso que hacían los negros, hispanos y mujeres de las actas de derechos civiles, el desprestigio internacional por la guerra de Vietnam, la humillación nacional por los rehenes en Teherán y el "engaño" de la URSS.

Estas percepciones, aunque parciales, nos permiten comprender por qué la opción liberal fue presentada como una amenaza contra la república, contra el poder adquisitivo de sus ciudadanos, contra la igualdad de oportunidades y la dignidad de la nación. Escapan a este manejo ideológico del liberalismo, las explicaciones de corte macroeconómico sobre los cambios en las relaciones de Estados Unidos y el mundo o análisis sobre las transformaciones políticas del país a través de la reconstitución de sus consensos y coaliciones.

Era de esperarse que, en el contexto electoral de 1988, estas interpretaciones generaran una respuesta contundente. Así, días antes del 8 de noviembre, salió publicado en la prensa estadunidense un manifiesto intitulado: "Una reafirmación de principio". Lo suscriben sesenta y cinco personalidades de la academia y la política, en-

17 "Strange Death of Liberal America", The Economist, 24 de septiembre de 1988.

18 Porcentaje obtenido de una escuesta realizada por The New York Times/CBS New, en septiembre de 1988. 
tre los que están: Daniel Bell, John Kenneth Galbraith, Clifford Greetz, Robert S. McNamara y Arthur M. Schlesinger Jr. Ellos declaran textualmente:

Nosotros hablamos como ciudadanos americanos que deseamos reafirmar la tradición liberal de Estados Unidos. En la fundación de nuestro país, el espíritu del liberalismo empapó la Revolución, la Declaración de Independencia, la Constitución y el Acta de Derechos. [...]

Nosotros lamentamos que el presidente de los Estados Unidos haya encabezado la denigración de una de nuestras tradiciones más antiguas y nobles. El se burló de la temible "palabra-L" y continúa haciendo de lo "liberal" y del "liberalismo" términos de oprobio.

[...] Los principios liberales - libertad, tolerancia y la protección de los derechos de cada ciudadano - son atemporales:

[...] Nos sentimos obligados a manifestarnos contra cualquier fomento de esta tendencia, internacional o no, en nuestro país. Esperamos que otros lo harán también. ${ }^{19}$

Asimismo, de manera complementaria, el reconocido historiador Arthur M. Schlesinger Jr. publicó en el Wall Street Journal una defensa del liberalismo, donde sustenta históricamente las aportaciones de esta tradición y de los presidentes liberales de este siglo, a los Estados Unidos. Considera que el significado negativo y peyorativo que se le ha atribuido a este término, es producto de una manipulación ideológica de la crisis que generaron los gobiernos conservadores entre 1968 y 1980: los de Richard Nixon, Gerald Ford e incluso el de Jimmy Carter, quien ha sido el presidente demócrata más conservador desde Grover Cleveland. Esta crisis continuó durante el mandato de Ronald Reagan, aunque de manera más o menos encubierta. Los datos de los déficit gemelos, la deuda nacional, la pobreza, los sin hogar, etc., hablan por sí mismos. En otras palabras, Schlesinger argumenta que los errores y fracasos de veinte años de gestiones conservadoras se han atribuido al liberalismo, causando su desprestigio. ${ }^{20}$

Estas dos inserciones en diarios norteamericanos expresan una defensa vigorosa de la libertad y el respeto de creencias, así como -en el segundo caso- una honda convicción y un gran orgullo de ser liberal hoy.

Hasta aquí hemos visto la importancia del uso ideológico del liberalismo; sin embargo, la evolución y ruptura de los constituyentes liberales de la cultura estadunidense se da en una dimensión más profunda. Es lugar común considerar que el consenso liberal de mediados de los cuarenta a mediados de los sesenta, estuvo sustentado en el modelo keynesiano de economía, las políticas sociales del New Deal de Roosevelt, una orientación internacionalista y una dominación patriarcal de los protestantes blancos anglosajones. Este consenso empezó a resquebrajarse en los sesenta y setenta debido a la contracultura, al movimiento feminista, a los grupos de izquierda, así como al rechazo de la guerra de Vietnam; y continuó a fines de los setenta con la rebelión fiscal populista. Ya en los ochenta, los movimientos de revivificación conservadora y religiosa

19 "A Reaffirmation of Principle", The New York Times, 26 de octubre de 1988.

20 Arthur M. Schlesinger, "Hurrah for the L-word", Wall Street Journal, de 21 de octubre de 1988 . 
pasaron a primer plano, por ser característicos de periodos de abundancia y expansión económica. ${ }^{21}$ La ruptura más significativa e irreversible de este proceso fue la impugnación de la autoridad general del grupo hegemónico, como resultado de la reivindicación de los derechos de las mujeres. A la rebelión contra la autoridad le siguió, en los años ochenta, la rebelión contra la modernidad, expresada por una fuerte corriente cultural de alcances mundiales que reclama las tradiciones y la continuidad en contra del universalismo y el laicismo. ${ }^{22}$

Por último, lo que interesa destacar aquí es el correlativo de este panorama cultural en la política. Los partidarios del New Deal aspiraban a un modelo político que guardara un equilibrio entre la concentración de poder en la economía y en el gobierno federal. Durante los primeros años, esta estructura estuvo legitimada por una ciudadanía nacional (con identidad compartida), que terminó por desmembrarse debido a la inmensidad de la nación y al gran número de intereses diferentes que contenía. Se tendió, entonces, al ideal del "Estado neutral" o al llamado "liberalismo de grupos de interés" para legitimar la concentración de poderes. Se asumió una posición pluralista fundada en la tolerancia, que niega de entrada la verdad moral absoluta; es decir, se deja a los individuos y a los grupos ejercer sus intereses y valores particulares, siempre que sean compatibles con libertades similares para otros. De esta manera, se aspira tanto a la neutralidad en cuanto a los principios que sustentan los derechos individuales, como a la neutralidad en cuanto a las políticas derivadas del liberalismo de grupos de interés. ${ }^{23}$

Esta práctica política de la neutralidad, regida por el respeto al otro y a los otros, encontró sus límites a principios de los ochenta. La creciente presión por cambios económicos y sociales exigía alternativas políticas definidas y de aplicación general. Además, el movimiento conservador atribuía al liberalismo una situación de decadencia social generada por su propia filosofía del pesimismo, la tolerancia y los derechos; y exigía al gobierno que promoviera la defensa de los valores y de la ética tradicionalista anticientífica de los norteamericanos como política.

En la década de los ochenta, la labor del descrédito ideológico del liberalismo y del resquebrajamiento de algunos de sus constituyentes culturales, políticos y económicos ha cristalizado -entre otros hechos- en la derrota de los candidatos demócratas a la presidencia de Estados Unidos.

\section{El estigma liberal o la "L-word"}

No hay duda de que Estados Unidos es un país de origen liberal. Su identidad se funda en un consenso básico en el que se encuentran enraizadas las tradiciones de libertad, derechos individuales, tolerancia y progreso. La mayoría de los norteamericanos se han reco-

21 Véase "El predicamento del liberalismo: Simposio", en Facetas, núm. 80, 2/1988, Washington.

22 Véanse Daniel Bell, Las contradiciones culturales del capitalismo, Madrid Alianza Universidad, 1977; Walter Dean Burhan, The Current Crisis in American Politics, Nueva York, Oxford University Press, 1982.

23 Véase Michael Sandel, Liberalism and its Critics, Harvard, 1987. 
nocido en ese consenso durante dos siglos, sin importar su filiación política.

Actualmente es lugar común referirse a la desarticulación del consenso liberal y al surgimiento de condiciones sociales, culturales, económicas e internacionales diferentes, sustentadas en la recomposición de coaliciones políticas y en la generalización progresiva de un consenso neoconservador. Con Reagan culminó la ruptura -iniciada en los sesenta - del modelo liberal de representación colectiva y surgió una nueva forma de pensar la política. El objetivo no es el equilibrio entre la concentración de poderes público y privado, sino polarizar la argumentación para privilegiar la retórica del big business sobre el big government.

De acuerdo con estos hechos, puede hablarse del término de un ciclo o de un largo periodo de la historia de Estados Unidos, e incluso referirse al fin del milenio. Pero lo que ha resultado indignante para el $15 \%$ de los liberales que se asumen como tales y para los demócratas en general, ha sido la burla que hizo Reagan del liberalismo al instituir la "L-word" y la forma como Bush estigmatizó a Dukakis como liberal.

No son nuevas las críticas al liberalismo en este país. Desde los sesenta, se han sucedido las recriminaciones de los estudiantes radicales por la guerra de Vietnam, el rechazo de los militantes negros al tipo de sociedad que se les ofrecía, el cuestionamiento de los grupos feministas al modelo de autoridad hegemónico y la impugnación de los neoconservadores a la decadencia social. Lo que ha llamado la atención es el manejo electoral y negativo del término, que contribuyó de manera decisiva al fracaso de Michael Dukakis.

Lo liberal ha llegado a ser lo innombrable. Se insinúa morbosamente con una " $L$ ", como si se tratara de un pecado o una obscenidad. Es la "letra escarlata" que marca y segrega. No sólo estigmatiza políticas fracasadas, también hiere los origenes y la esencia del ser norteamericano en las postrimerías del siglo $\mathrm{XX}$.

En 1988, el uso republicano de la "L-word" operó como una fatalidad para los demócratas. La opinión pública los identificó con todas aquellas actitudes y decisiones políticas que generaron el proceso de inflación sostenida de los setenta y principios de los ochenta, así como con manifestaciones alarmantes de decadencia social.

El cambio de significado del liberalismo fue radical. De ser el principio legitimador del sistema político y la sociedad norteamericana, pasó a representar su destrucción. Ahora ya no se concibe a los liberales como portadores de la libertad, la tolerancia y la defensa de los derechos de cada ciudadano, sino como a manipuladores perversos de la política que, a nombre de estos valores tradicionales, subordinan los intereses privados a los públicos, someten el individuo al estado y eliminan toda norma moral.

Esta asombrosa transvaloración de lo liberal, con sus connotaciones negativas, se gestó en la "Era Reagan" e irrumpió en el proceso electoral de 1988, como un arma descalificadora y maniquea que señaló a Dukakis como un mal para la república y a Bush como a la mejor alternativa para Estados Unidos.

El daño que causó el estigma liberal a los demócratas es inmenso. Además de la impostergable y difícil tarea de renovación política de su partido, se encuentran ideológicamente segregados 
por la "L-word". Borrar esta marca es uno de sus retos más urgentes. ¿Cómo lograrlo? Para empezar, el diseño de una contraimagen no se da en el vacío, por lo que requiere estar vinculada también con problemas estructurales. Así, frente a las astucias publicitarias está el trabajo político de reconstrucción programática y organizativa, que es prolongado e ingrato. $Y$ ante las dificultades de la coyuntura y el horizonte nebuloso, algunos podrían consentir la ilusión de la espera de un líder carismático o de un acontecimiento que fulminara a los republicanos y colocara en el primer plano de la escena política a los demócratas.

La derrota de Michael Dukakis mostró la imposibilidad que los demócratas tienen para definir el liberalismo hoy. Asimismo, reveló la necesidad de un cambio de estrategia partidaria, ya que no han logrado articular un proyecto nacional nuevo, una coalición politica fortalecida y un consenso alternativo al neoconservador. Como puede apreciarse, viven un conflicto de identidad que tiende a atrofiar sus perspectivas políticas. Su situación todavía es confusa, pues se encuentran entrampados en el debate del deber ser de la racionalidad política, la arbitrariedad del estigma liberal y el azar de los hechos históricos. 